\title{
The Realization of Code Switching: An Analysis of the Novices of Pre- Service Teachers in EFL Classroom
}

\author{
S.Thoriqul Huda ${ }^{1}$, Mujibul Hakim ${ }^{2}$, Muhammad Mizam ${ }^{3}$ \\ Universitas Selamat Sri, Institut Technologi dan Science NU, Universitas Pekalogan \\ Email: s.thoriqulhudaunissbatang@gmail.com ${ }^{1}$ \\ Email: mujibulhakim@gmail.com ${ }^{2}$ \\ Email: milzamlife@gmail.com ${ }^{3}$
}

\begin{abstract}
Code-switching is one of linguistic phenomenon in daily activities. The study aims at focusing on the novices of pre-service teachers' who use code-switching in EFL classroom. It also explains why the novices use code-switch in learning process. The study used qualitative approach. The data was recorded and transcribed to analyze why and how code-switching was used by nine novices in the classroom of MA NU Batang. The analysis of the classroom revealed that nine novices used code-switched in categorizing the forms of the utterances. The result shows that: (1) There are two ways in which the novices use code-switching in teaching and learning process, including form (word, phrase, and sentence) and function and condition was 132 or 55\% utterances of code-switching (2) The novices use code-switching from L2 to L1 including form (word, phrase, and sentence) in learning activities. (3) The reasons that the novices use code-switching in classrom is to help the students when they explain in difficult words, phrases or sentences the lesson. (4) The used of codeswitching make their students easier to understand what they are learning. Therefore, code switching has good effect in EFL classrooms to facilitate teaching and learning.
\end{abstract}

Keywords: Code-Switching, Linguistics, Pre-Service Teachers (novices), Sociolinguistics,

\section{INTRODUCTION}

Code-switching has an essential role in bilingual communities. It is one of the linguistic phenomenon in communication. Code-switching can be defined as an alternation of two or more languages in communication (Bhatti et al., 2018). In Indonesia, the students learn English as a foreign language, and they have the mother tongue as the first language. However, English has a particular space in the curriculum in
Indonesia. The English subject is still implemented in the national curriculum (Sofiana et al., 2019). Therefore, in learning activities, they often do communication in bilingual communities. They have reasons to do dialogue in code-switching that is to communication need. Bilingualism is a linguistic term referring to the fact that linguists have discovered significant alternations in phonology, morphology, and syntax in studying verbal 
behavior of a particular population (Brice, 2004). Being bilinguals can increase someone's ability to choose the words in distracting the information (McDonald, 2013 in Schwartz 2011). It is the norm worldwide, and code-switching and codemixing occur only in the speech of bilinguals (Brice, 2004).

These norms require that both languages be used in this way so that conversant can show their familiarity or solidarity. A speaker may similarly switch to another language or mix languages (code-mixed) as a signal of group membership and shared ethnicity with an addressee, ( Sighn, 1996 in Mesthrie, 2009).

(Crystal, 2003) suggests -where two bilingual speakers were accustomed to conversing in a particular language, codeswitching to others was bound to create a special effectll. So, the notions suggest that codeswitching might be used as a sociolinguistic tool by bilingual speakers. (Cerqua, 2004) says - the main motivations to switch or mix: to joke, means of expression, lack of language knowledge, change in members, and to maintain a sense of comfort. A varying degree of codeswitching may also be used between bilingual conversationalists depending on the person being addressed, such as family, friends, officials and superiors and depending on the location, such as home or place of work (Crystal, 2003).

Concerning the code-switching, this study aims at analyzing the code-switching in the teaching process, especially on the novices of pre-service teachers use code-switching in (between Indonesia and English). Novice is a person who is new and has little experience in a job or situation (Stevenson \& Waite, 2011). They trained to do teaching practice at Madrasah Aliyah of Nahdlotul Ulama in Batang. Thus the realization of code-switching refers to the students who have trained by the novices when in the classroom.

The researcher assumes that novices in this case: for pre-service teachers' code-switch and when they taught the learners of Madrasah
Aliyah of Nahdlotul Ulama in Batang in the classroom. Some of the most common ways for the effects of language contact to be manifested in speech are through phenomena such as inference, transference, and code-switching.

A number of researchers who have conducted of code-switching research (Wang, 2018; Alhourani, 2018; Banatao \& MalenabTemporal, 2018) state that code-switching is linguistic phenomena that have social function as language facility for communication in society. It has important effect for helping the person to attain the goal of communication. Moreover, (Bullock \& Toribio, 2009) Code-switching (CS) is but one of a number of the linguistic manifestations of language contact, which variously include borrowing on the lexical and syntactic levels, language transfer, linguistic convergence, interference, among others. In short, code-switching is the mixing of the words, phrases and sentences from two distinct grammatical systems across sentence boundaries within the same speech event.

Besides, (Horberger \& Mc Key, 2010) cited in Gardner-Chloros (1985), also emphasize that code-switching can occur not only between languages but also dialects of the same language. Horberger (2010) adopted from Gumperz (1992) defines the terms -code-switching as the juxtaposition within the same speech exchange of passages of speech belonging to two different grammatical reasons for code-switching.

Therefore, the researcher analyzed the effects of language contact that it is caused by code-switching. The present study investigated the novices of pre-service teachers in teaching process in EFL classroom, such as: (1) What are the ways of using code-switching? (2) What are the forms that use in code-switching in learning activities? (3) What are the reasons of novices used code-switching? (4) What are the effects of using code-switching for the learners? 


\section{METHOD}

This research is a case study and the case study belong to qualitative research. To get the natural data, the writer explained the reasons or the aim of the study that was to know the way novices code-switch also to get information of some reasons why they code-switch from English into Indonesian.

Different researchers have different purposes for studying cases. That case is studied because the researcher wants to have better understanding of this particular case. As a research design, case study claims to offer a richness and depth of information not usually offered by other methods (Hancock, 2002).

Related to Jennifer A. Rose-Woodward, M.S. The nature of this study was to gather authentic information from professionals in an established educational setting. In the study, the validity of the faculty "s underlying knowledge was crucial. For that reason, the researcher pursued a -key rolel as an interviewer, listener, and data collector (Cresswell, 2007). The researcher did not assert any personal views, nor biases in regard to the topic, but allowed the experts" views to provide the basis for the discussion.

Besides, Creswell (2007) described this method as using the views from the participants' interviews, rather than the researcher's own, as employing, participants' meanings. More simply stated, the participants thoughts and beliefs guided the study. Open-ended questions that invited each participant to discuss and elaborate on the subject of students' academic writing were asked. Moreover, to further encourage the faculty members to expand on the subject, the researcher created a sincere listening environment to let the participant know that she was providing important information for the study. As all data was digitally recorded for accuracy, the researcher maintained eye contact throughout the interview. Those were the descriptions on qualitative approach that was used in this research.
The setting of the research was at MA NU Batang, Jl. Jend A. Yani 114 Kauman, Batang. The reason for conducting the researcher at MA NU Batang that is one of the a Private Senior High Schools applying the 2006 curriculum of provincial level local content. The Number of classes consist of six classes related to the Novices' classes

This study is a descriptive qualitative research and the researcher becomes the main instrument of the study. The data needed for this study are in the form of transcription record of the novices. Talk closing the English teaching learning process in the class room.

The former were collected through observation, and the latter were collected through interview. The interview was conducted to the novices as well as the teachers. Again, these interviews were E-recording.

The first step the writer asked for permission to conduct the research at MA NU Batang and talked to the novices and the novices' advisors of the school about the aim of the study. The next steps the writer was negotiated with four novices who teach in the in the room activity of the school. The writer made an appointment and set the time.

Table 1 The time Scedule of the process of conducting the research in the field

\begin{tabular}{|c|c|c|c|}
\hline Time & Place & Activities & Person involved \\
\hline $\begin{array}{c}2^{\text {nd }} \text { week } \\
\text { Oktober } 2019\end{array}$ & $\begin{array}{c}\text { MA } \\
\text { NU Batang }\end{array}$ & $\begin{array}{c}\text { Preparing } \\
\text { administration }\end{array}$ & Researcher \\
\hline $\begin{array}{c}3^{\text {rd }} \text { week } \\
\text { Oktober } 2019\end{array}$ & $\begin{array}{c}\text { MA } \\
\text { NU Batang }\end{array}$ & $\begin{array}{l}\text { Observation and } \\
\text { Making an } \\
\text { appointment with } \\
\text { the Novices }\end{array}$ & Researcher \\
\hline $\begin{array}{c}4^{\text {th }} \text { week Oktober } \\
\text { '15- } 1^{\text {st }} \text { week } \\
\text { Desember } \\
2019\end{array}$ & $\begin{array}{c}\text { MA } \\
\text { NU Batang }\end{array}$ & $\begin{array}{l}\text { Observing, } \\
\text { Recording } \\
\text { through out the } \\
\text { Novices when } \\
\text { they were } \\
\text { teaching in the } \\
\text { class room }\end{array}$ & $\begin{array}{c}\text { Researcher } \\
\text { Students of MA }\end{array}$ \\
\hline $\begin{array}{c}1^{\text {st }} \text { week } \\
\text { Desember } 2019\end{array}$ & $\begin{array}{c}\text { MA } \\
\text { NU Batang }\end{array}$ & $\begin{array}{l}\text { Conducting the } \\
\text { Interview }\end{array}$ & $\begin{array}{l}\text { Researcher } \\
\text { Students } \\
\text { of MA }\end{array}$ \\
\hline
\end{tabular}




\begin{tabular}{|c|c|c|c|}
\hline $\begin{array}{c}2^{\text {nd }} \text { week } \\
\text { Desember } 2019\end{array}$ & $\begin{array}{c}\text { MA } \\
\text { NU Batang }\end{array}$ & $\begin{array}{l}\text { Analyzing the } \\
\text { result of the } \\
\text { result } \\
\text { Analyzing all } \\
\text { data by } \\
\text { computation } \\
\text { process }\end{array}$ & Researcher \\
\hline $\begin{array}{c}3^{\text {rd }} \text { week } \\
\text { Desember } 2019\end{array}$ & $\begin{array}{c}\text { MA } \\
\text { NU Batang }\end{array}$ & $\begin{array}{l}\text { Reporti } \\
\text { ng the data in } \\
\text { thesis }\end{array}$ & Researcher \\
\hline
\end{tabular}

In addition, the subjects of the study were the Pre-Service English Teachers of Unikal Pekalongan. The researcher chose them as the subjects of the study because they are able to comprehend English, Indonesian and Javanese rule in using those languages. Besides, they speak at least one variety of Javanese: the Ngoko or the Krama variety.

The researcher tried to know the way the novices code-switch. The teacher's way in teaching while explaining the lesson in the class room influences the lessons. Hence, the teacher plays an important role in the class room, especially English as a foreign language most interactive in the classroom have the objectives of requesting and giving information. Besides, that the teacher also would get information, whether code-switching that reflects the novices' skill or deficit at MA NU Batang.

\section{RESULT AND DISCUSSION}

\section{The Way Novices Code-Switch in Teaching and Learning Process at MA NU Batang?}

There are two ways in which the novices codeswitch in teaching and learning process, including form (word, phrase, and sentence) and function and condition. Firstly, novices do codeswitching based on the form, including words, phrases and sentences. It could be supported by the data as can be seen on table 2 Based on this table, the researcher could categorize the way novices do code-switching. The code-switching is 132 or it is $55 \%$ utterances of code- switching. The way can be seen from the form of utterances of code-switching made by I. In table

2 , there are 53 utterances of code-switching.

Table 2 The summary of utterances of code-switching made by $I$ in the classroom.

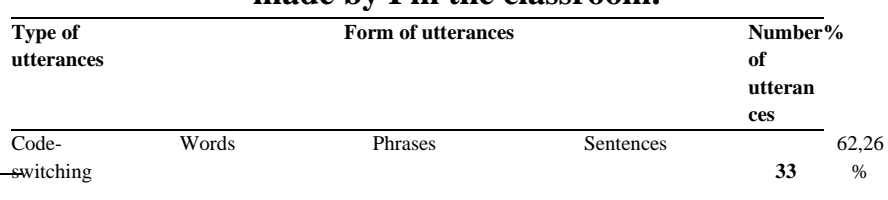
$\begin{array}{lllllllllllllll}\text { Number } & 0 & 0 & 0 & 0 & 1 & 3,03 \% & 0 & 0 & 32 & 96,96 \% & 0 & 0 & 33 & 100 \%\end{array}$ and

In the first group there are 33 utterances of codeswitching and there are no utterances in the form of word. There is 1utterance of code-switching in the form of a phrase. It means that there is only $3,03 \%$ utterances of code-switching in the form of a phrase. That is, utterance of code-switching in the form of phrases is number $(27 / \mathrm{CS})$. The high number of utterances of code-switching in table 4.1 is in the form of Indonesian sentences. There are 32 Indonesian utterances of codeswitching made by I or it was $96.96 \%$ from the total number of code-switching utterances.

Table 3 The summary of utterances of code-switching made by LMA in the classroom.

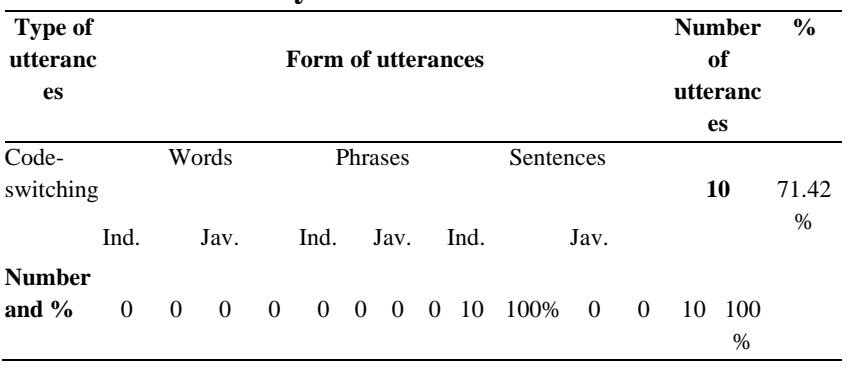

The code-switching utterances made by LMA are divided into three classifications. First, there is no code-switching utterance in the form of word. There is also no code-switching utterance in the form of Indonesian phrases. The third is code-switching utterance in the form of sentences. The Indonesian code- switching utterances in the form of sentences are 10utterances or it is $100 \%$ from total number of code-switching utterances.

The next is the number of utterances made 
by LRW. There are 16 utterances of codeswitching.

Table 4 The summary of utterances of code-switching made by LRW in the classroom.

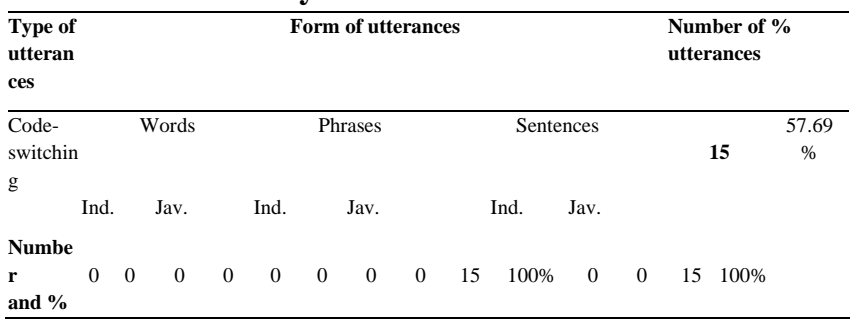

The total number of code-switching utterances is 8 utterances or it is $50 \%$ utterances of code-switching and all of them are Indonesian sentences. There are 8 utterances of Indonesian sentences made by LRW, for example utterances of code-switching in the form of Indonesian sentences are numbers (2/CS), (3/CS), (5/CS). It means that there are $100 \%$ utterances from total number of code- switching utterances.

Table 5 The summary of utterances of code-switching made by $\mathbf{G H}$ in the classroom.

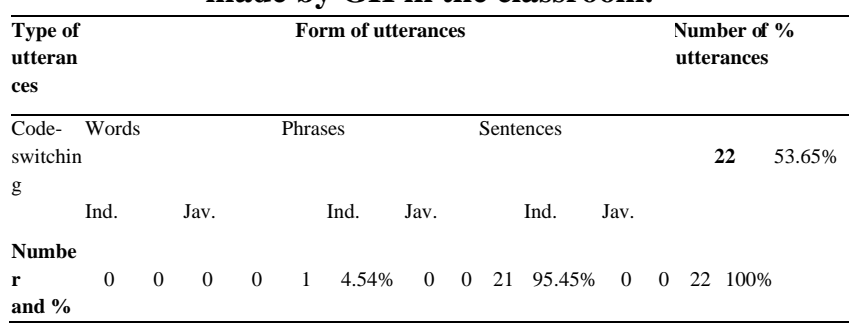

The next is utterances of code-switching made by GH. He made 41 utterances of codeswitching when he was teaching in his classroom. The 41

utterances are divided into two classifications. The first is the group of codeswitching utterances. In this group are 22 utterances. The 22 utterances are in the form of Indonesian sentences and in the form of phrases. The utterance of Indonesian sentence is 21 or it is $95.45 \%$ from total number of code-switching utterances. For examples utterances number (1/CS), (5/CS) and (9/CS) while the utterances of Indonesian phrase is only 1 utterance, or it is $4,54 \%$ from the number of code-switching utterances. This utterance is number (11/CS).

In table 4.5, the researcher described utterances of code-switching made by NN. She made 33 utterances of code-switching when she was teaching in her classroom.

Table 6 The summary of utterances of code-switching made by $\mathrm{NN}$ in the classroom.

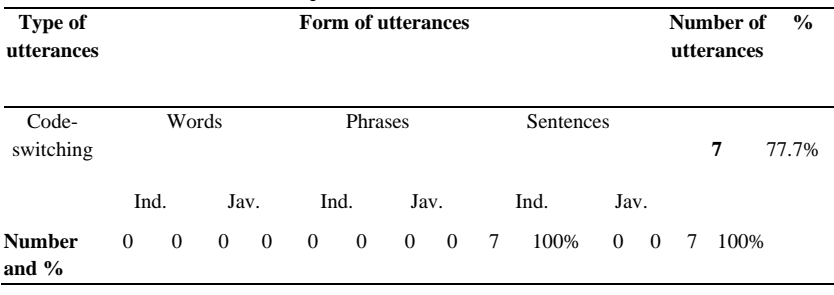

She made 13 utterances of code-switching. All of them are Indonesian sentences for codeswitching of example, (1/CS), (2/CS) and (4/CS). it means that she made $100 \%$ utterances of codeswitching in the form of Indonesian sentences.

Table 7 The summary of utterances of code-switching made by NSP in the classroom.

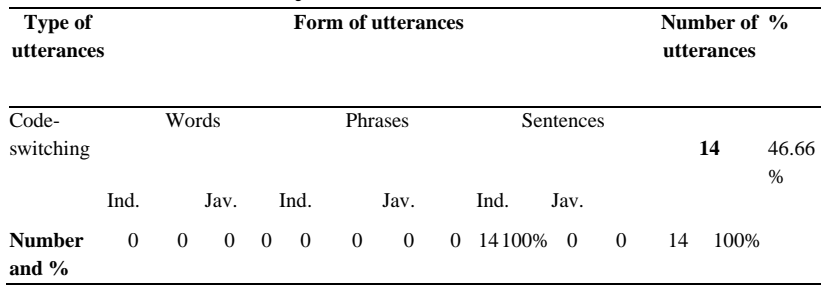

There are 30 utterances of code-switching utterances made by NSP. It is stated in table 11 . There is no code-switching utterance in the form of Indonesian word and Indonesian phrase. while the utterances of code-switching in the form of Indonesian sentences are14 utterances or it is $100 \%$ code- switching utterances of Indonesian sentences for example, (1/CS), (3/CS) and (4/CS).

Table 8 The summary of utterances of code-switching made by $Y P$ in the classroom.

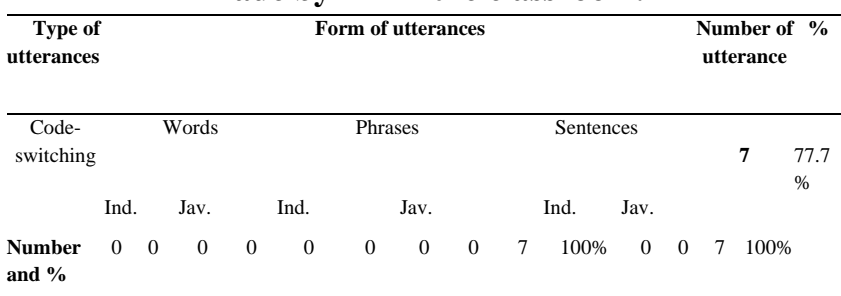


Table 13 is the categorization of utterances related to code-switching It made by YP in her classroom. She made 9 utterances of codeswitching. In the group of code-switching utterances there are 7 utterances or it is only $77.7 \%$ from the total number of utterances. In the code-switching classification, there are no utterance of Indonesian word and Indonesian phrase. Then there are 7 utterances of Indonesian sentences made by YP when she was teaching English in her classroom for example utterances number (1/CS), (2/CS) and (3/CS). The 7 utterances of code-switching are the same with $100 \%$ from the total number of code-switching.

Table 9 The summary of utterances of code-switching made by NLF in the classroom.

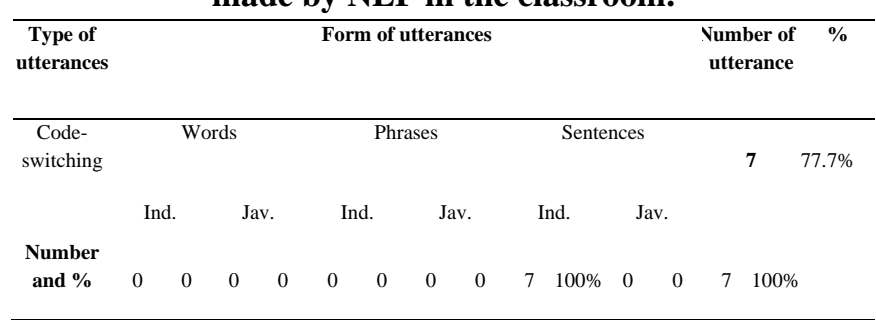

In table 15 , there are code-switching utterances. In this group there is no codeswitching utterance in the form of Indonesian word and Indonesian phrase. While the utterances of code-switching in the form of Indonesian sentences are 10 utterances or it is $100 \%$ code-switching utterances of Indonesian sentences, for example (1/CS) and (2/CS).

Table 10 The summary of utterances of code-switching

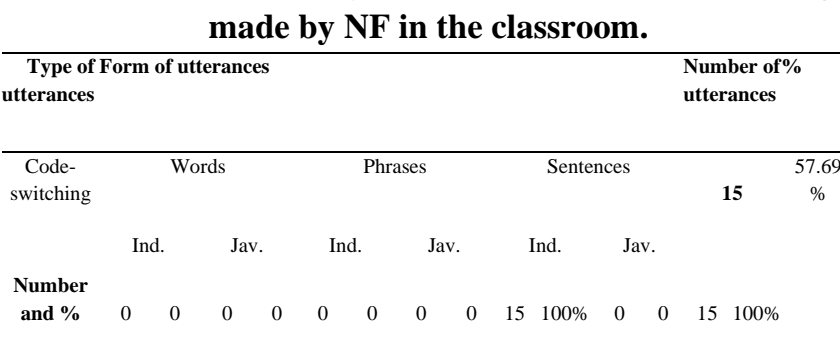

Table 4.9 is the last categorization of utterances related to code-switching made by NF in her classroom. She made of code-switching utterances there are 15 utterances or $57,69 \%$ from the total number of utterances. In the codeswitching utterances there are no utterance in the form of Indonesian word and Indonesian phrase. And there are 15 utterances of Indonesian sentences or it is $100 \%$ of the total number of code-switching utterances made by NF when she was teaching in her classroom. For example utterances number (1/CS), (2/CS) and (3/CS).

\section{DISCUSSION}

\section{The Way Novices Code-switch in English Language Teaching and Learning Process?}

To answer the first problem of this study, the researcher analyzed the utterances of codeswitching made by the nine novices. It means that the researcher would like to explain novices code-switch in teaching learning process at MA NU Batang.

There were two ways the novices do code-switching in teaching and learning process. The first way was based on the form (word, phrase, and sentence) and the second way was the function and condition of utterances of codeswitching made by the nine novices.

Firstly, novices do code-switch based on the form, including words, phrases and sentences. It was found that the Word levels are 0 utterances, the Phrase levels are 2 or $1,51 \%$ utterances and Sentence levels are 130 or $98,48 \%$ utterances. The sentence utterances dominated through other utterances. It indicates that the in a one sentence made the students ease to communicate more effectively. Another reasons the sentences make the teachers ease to convey more exact meaning and to reiterate the point to communicate more effectively.

Code-switching may therefore be seen as fulfilling the relational and referential function of language. Likewise in accordance with Halliday's (1975) functions of language, code-switching may be seen as -fulfilling the interpersonal function, i.e., languages as a 
mediator of rulell. In other words, it is the use of language to act as a mediator between self and other participants in the situation of communication.

The nine tables are the following. Table 4.19 is the summary of function of codeswitching utterances made by I. I made 53 utterances of code-switching. There are 53 utterances of code-switching which are classified into the function and condition of utterances. The first function of 13 or $24.52 \%$ of utterances is to appeal to the illiterate. She also made 2 utterances or $3.77 \%$ to convey more exact meaning. The third is a group of utterances which function is to ease communication. This group consists of 3 utterances or it is $5.66 \%$ from the total number of utterances. The next are utterances which function is to reiterate the point. The number of utterances in this function is 31 utterances or $58.49 \%$ and there are 4 utterances or $7.54 \%$ which function to communicate more effectively. The second classification is based on of the condition in which the utterance, uttered. There are 2 utterances or $3.77 \%$ which the speaker made because of lack of one word in either language. The next is a group of utterances which the speaker uttered because he wishes to create a certain communication effect. This group consists of 26 utterances or it is $49.05 \%$. I made 25 utterancesor $47.16 \%$ of the total number of utterances. Whose function is to make a point. Thus, from the analysis, it can be inferred that the main function of code-switching is to reiterate the point. And the highest number of the condition is one wishes to create a certain communication effect.

Table 4.20 is the summary of codeswitching utterances made by LMA. There are 14 utterances of code-switching in this table. The dominant function of code-switching utterances is to reiterate the point. It is 11 utterances or $78.57 \%$ from the total number of utterances.

The next function is to convey more exact meaning. The number of this function is 2 utterances or $14.28 \%$ from total number of utterances. The last function of utterances of code-switching made by LMA is to ease communication. There is only one utterance of code-switching $7.14 \%$ from the total number of utterances.

The next is the analysis of the condition of utterances made by LMA. There are 3 conditions in which LMA code-switched. The first is one is lack of one word in either language. In this function there are 2 utterances or $14.28 \%$ from the total number of utterances there are 4 utterances or $28.57 \%$. The next condition produced in this condition is one wishes to create a certain communication effect. The last condition of utterances is one wants to make a point. There are 8 utterances or $57.14 \%$ from the total number of utterances produced in this condition.

The next is utterances made by LRW. There are 3 functions of code- switching utterances made by LRW. The first function is to convey more exact meaning. There is only one utterances of code-switching in this function which form $6.25 \%$ from the total number of utterances produced in this condition.

There are 5 utterances which function is to ease communication or it is $31.25 \%$ from total number made by LRW in her class when she was teaching English. The next function is to reiterate the point. The number of this function of codeswitching are 10 utterances or $62.5 \%$ from total number of utterances produced in this condition.

The second group is a group of the analysis of the condition of utterances. There are 3 conditions of utterances made by LRW. There is 1 utterance or it is $6.25 \%$ which condition is lack of one word in either language. the second condition is one wishes to create a certain communication effect. In this condition there are 7 utterances or $43.75 \%$ from the total number of utterances. And the last there are 8 utterances or $50 \%$ which condition is one wants to make a point.

The next is table 4.22 There are 41 utterances of code-switching made by GH. The 
first function of code-switching utterances is to appeal to the illiterate. There are 11 utterances or $26.82 \% \%$ from the total number of utterances of code-switching.

The next function is to ease communication. The number of the functions of utterances code-switching in this summary are 6 utterances or $14.63 \%$ from the utterances made by $\mathrm{GH}$. The third function made by $\mathrm{GH}$ is to reiterate the point. Further there are 23 utterances of code-switching $56.09 \%$ from all utterances. The last function is to communicate more effectively.

The use of code-switching in the classroom would provide for bilingual norm whereby code-switching is seen to be acceptable method of communication. Code-switching may be viewed as an extension to language for bilingual speakers rather than interference and from other perspectives. It may be viewed as interference, depending on the situation and context in which it occurs

It is essential to maintain and to establish relationships. Therefore, interference needs to be dealt with in EFL class learners tend to pick up specific work related to language at specific situation; what they find much more difficult is the acquisition of general communication strategy.

It may be argued if language teachers just provide learners with reasonable pronunciation, an adequate selection of structures and vocabularies and make sure that they can fit the language to particular functions, then leave them to put this knowledge into practice.

In the section of condition, NSP made 3 conditions of utterances. The first condition is some concepts are easier to express in one of the language in which there is only 1 utterance or it is $3.3 \%$. The second condition is one wishes to create a certain communication effect. There are 9 utterances or it is $30 \%$. The last condition, there are 20 utterances or $66.6 \%$ of the total number of utterances made by NSP in her classroom.

Secondly, the classification is the analysis of condition of utterances, and there are only two conditions made by YP. The first is one wishes to create a certain communication effect in which there are 6 utterances or it is $66.6 \%$. The second condition is one wants to make a point in which there are 3 utterances or $33.3 \%$ from the total number of utterances produced in this condition.

The next table is the summary of utterances made by NLF. There are 18 utterances of code-switching in table 16. The first function of code-switching utterances is to appeal to the illiterate. The next function is to convey more exact meaning in which there are 4 utterances or $22.2 \%$.

The first condition of utterance made by NLF is one lack of one word in either language in which there are 4 utterances or $22.2 \%$. The second is some concepts are easier to express in one of the language. There is 1 utterance or $5.55 \%$. Beside that there are 7 utterances or $38.8 \%$ which condition is one wishes to create a certain communication effect. The last condition is one wants to make a point in which there are 6 utterances or $33.3 \%$ from the total number of utterances made by NLF in her classroom.

There are 3 conditions of utterances made by NF. She made 2 utterances or $7.69 \%$ from all utterances and the second condition is one wishes to create a certain communication effect in which there are 14 utterances or $53.84 \%$ while the last condition is one wants to make a point in which in this section there are 10 utterances or $38.46 \%$ from the total number of utterances made by NF in her classroom.

There are some relevant relations between the study discussed on code switching on processing of foreign language learning, especially for high school students. First, English teachers can explain about the correct use and position of sentences/utterances easily words choice. Hopefully, students will be able to make grammatical sentences/utterances in order to eliminate misunderstandings and ambiguity in their interactions. The teachers should use authentic materials to set standards for code 
switching in the students' work by exercising something interesting for the students.

Many people, especially students, novices, teachers, and also executives change over words, phrases, clauses, or sentences in their utterances. Interestingly the habit of codeswitching does not only occur in an informal talk in some places but also in formal places, for example, in the school, and in the offices, etc.

This study was motivated by a simple question; what exchange of structures are found in code switching produced by the novices during the teaching and learning process? This calls for an analysis of the exchange structure which performs the structure of initiate-response-follow up formation as the characteristics of certain teaching and learning process.

This study also describes the move structure that is formed as the combination of acts. Those will be the analytical categories and a clear understanding of the realities of English conversation in the class room for the students to apply with confidence towards an improved ELT pedagogy.

Finally, the researcher should also note that this study, a speaker may not be able to express him or herself in one language, so he or she code-switches to the other languages to compensate for the deficiency. Consequently, code-switching commonly occurs when an individual wishes to express solidarity with a particular social group, so, the researcher suggests that code-switching might be used as a sociolinguistic tool by bilingual speakers. Therefore, there is an obvious need for more studies to investigate which will find the different findings in many different genres.

\section{CONCLUSION}

The conclusions are as follows: This study was conducted to explain how novices code-switch in teaching learning process at MA NU Batang, From the analysis it could be concluded that the total number of utterances of code-switching is in the form of sentences. The total number $\mathrm{f}$ utterances of code-switching made by nine novices of English classes of senior high school are 240 utterances. The 240 utterances are classified into two classifications. The first is 132 or it is $55 \%$ utterances of code-switching

In addition, there are 4 conditions of utterances made by nine novices. The highest number of the condition is one wishes to create a certain communication effect in which there are 118 utterances or $49.16 \%$. And the second condition of utterance is one wants to make a point that there are 97 utterances or $40.4 \%$ from the total number of utterances. The next condition is one lack of one word in either language in which there are 23 utterances or $9.58 \%$. While the lowest number of the conditions is some concepts are easier to express in one of the language in which there are only 2 utterances or it is $0.83 \%$ from the total number of utterances made by nine novices.

Based on the answers from the recording of interview, it can be synthesized that the novices code-switch not because of their deficit for using English as means of communication in teaching learning process. On the other hand, they code-switch because of their skill to make their students understand what they are learning. Especially when there were English difficult words, phrases, and sentences so here the novices code-switch not because of their deficit to speak English continuously.

\section{REFERENCES}

Alhourani, D. A. Q. (2018). International Journal of Linguistics, Literature and Translation (IJLLT) ISSN: 2617-0299 www.ijllt.org. International Journal of Linguistics, Literature and Translation, 10.

Banatao, M. A. B., \& Malenab-Temporal, C. (2018). Code-Switching in Television Advertisements.pdf. TESOL International Journal, 13(4). 
Bhatti, A., Shamsudin, S., \& Said, S. B. M. (2018). Code-Switching: A Useful Foreign Language Teaching Tool in EFL Classrooms. English Language Teaching, $\quad 11(6), \quad 93$. https://doi.org/10.5539/elt.v11n6p93

Brice, A. (2004). Code-switching: A primer for Speech-language Pathologists. Texas Journal of Audiology and Speech Pathology.

Bullock, B., \& Toribio, A. (2009). Psycholinguistics and code-switching. In, The Cambridge Handbook of Linguistic Code-switching.

Cerqua, S. (2004). Mingling: Codeswitching/Mixing Practices of North American Bilinguals. The Internet TESL Journal.

Cresswell, J. W. (2007). Research Design: Qualitative and Quantitative Approaches. SAGE Publications, Inc.

Crystal, D. (2003). The Cambridge Encyclopedia of Language (2nd edn). Cambridge University Press.

Hancock, B. (2002). Trent Focus for Research and Development in Primary Health Care: An Introduction to Qualitative Research. Trent Focus Group.

Horberger, H. N., \& Mc Key, S. L. (2010). Sociolinguistics and Language education. Britain by Short Run Press Ltd.

McDonald, K. (2013). The Importance of Students' Learning French as a Second Language.pdf. BU Journal of Graduate Studies in Education, 5(2).

Mesthrie, R. (2009). Introducing Sociolinguistics (2nd Edn). Edinburgh University Press.
Sofiana, N., Mubarok, H., \& Yuliasri, I. (2019). English Language Teaching in Secondary Schools: An Analysis of the Implementation of Indonesian ELT 2013 Curriculum. International Journal of Instruction, 12(1), 1533-1544. https://doi.org/10.29333/iji.2019.12198a

Stevenson, A., \& Waite, M. (2011). Oxford Dictionry (12 edition). Oxford University Press.

Wang, H. (2018). Interpersonal meaning of codeswitching: An analysis of three TV series. Australian Journal of Applied Linguistics, 1(1), 3-19. https://doi.org/10.29140/ajal.v1n1.4 